\title{
A quick-scan appraisal method to determine cost-effectiveness of Traffic and Demand Management measures
}

Prof. Dr. Henk Meurs,

MuConsult/ Radboud University

P.O. Box 2054, 3800 CB Amersfoort

Phone: +31653426200

E-mail: h.meurs@muconsult.nl

Prof. Dr. Bert van Wee

Delft University of Technology

Faculty of Technology, Policy and Management

Section Transport and Logistics

Jaffalaan 5, PO Box 5015, 2600 GA Delft - The Netherlands

Phone $+31(0) 152781144$

Fax $+31(0) 152782719$

Email g.p.vanwee@tudelft.nl

Drs. Jan Perdok

Senior Project Manager

MuConsult

Utrechtseweg 24, PO Box 2054, 3800 CB Amersfoort - The Netherlands

Phone $+31(0) 3353426467$

Fax $+31(0) 334614021$

Email j.perdok@muconsult.nl

Prof.dr.ir. Serge Hoogendoorn

Delft University of Technology

Faculty of Civil Engineering and Geosciences

Department of Transport \& Planning

Stevinweg 1, PO Box 5048, 2600 GA Delft - The Netherlands

Phone +31152785475

Fax +31152783179

e-mails.p.hoogendoorn@tudelft.nl

\begin{tabular}{|l|r|}
\hline Word count \\
\hline Abstract & 169 \\
Main text & 5400 \\
Figures $(2 \times 250)$ & 500 \\
Tables $(2 \times 250)$ & 500 \\
\hline Total & $\mathbf{6 5 6 9}$ \\
\hline
\end{tabular}

Key Words: cost effectiveness, traffic management, demand management 


\begin{abstract}
This paper presents this quick-scan approach for assessing the cost-effectiveness of smaller and not-well demarcated transport measures that can be used as a first-scan while establishing packages to deal with certain transport problems. It adds to the available evaluation literature (see section 2) in relying on a combination of expert opinions as well as simple models rather than data intensive four-stage transport models. The approach consists of five steps, in the end yielding to an assessment of the cost-effectiveness of the considered measure.
\end{abstract}

We illustrate the approach by applying it to determine the cost-effectiveness of a pricing measure, showing both the workings of the approach and the plausibility of the results.

We conclude that the proposed method is applicable for providing a first, quick scan assessment. This assessment is useful in the first selection of planning, to support policy makers that need to choose in which (selection of) measures they need to invest, even if these measures have not yet been described or designed at a very detailed level.

\title{
INTRODUCTION
}

The number of car miles in The Netherlands has increased by 14 percent, while the travel time losses on freeways increased by 55 percent in the period 2000-2008 (KIM, 2010). In the following period $2008-2010$, we observe stabilized car miles and a drop in travel time losses (KiM, 2011). Until recently, policy makers tried to reduce the (expected) increase in travel time losses to some extent by increasing the capacity of freeways and by improving transit. However, the economic situation calls for cutting public spending, including reluctance with respect to investing in road and rail infrastructure. Therefore, the Dutch Ministry of infrastructure and the Environment decide to launch a Program on Improved Utilization of Existing Infrastructure (I\&M, 2010), which focuses on using available infrastructure better by managing demand and supply in time and space in a more efficient way.

This program is specifically aimed at cooperation between the national and regional governments as well as with companies in an innovative way in order to achieve improved utilization of existing networks especially in peak hours, by:

- Travel-demand-oriented policies aiming at a better spread over the day in the use of the entire network, modal shifts, change in the timing of travel, and so on. This mainly means that road users (passengers and freight) will be offered more alternative choices to driving in peak hours. These measures include options for commuting outside rush hours by being better informed about travel options;

- Supply-oriented policies: increasing the available capacity of the infrastructure networks and optimize these by connecting them in a smart manner. This may include minor adjustments to physical characteristics of the network, improved park and ride, parking facilities for bicycles and so on. In addition, new impulses for use of navigation systems might be given, concentration of activities around transit stops are considered and agreements between road authorities on traffic management coordination could be arranged. In addition, development of technology by the market (service providers, ICT companies, etc.) will be stimulated, including navigation systems to guide traffic more smoothly. Finally, some policies on waterways will be included facilitating modal shifts in freight transport.

The measures to be taken should give noticeable results in ultimately 2014, although with the fall of the government in 2012 and the related change in government, this requirement has somewhat changed this urgency. A major part of the policies will be developed and implemented at a regional level, being subsidized by the national government. At this level a package of multimodal measures (roads, rail, regional public transport, cycling and waterways) will be developed, in which municipalities, counties as well as road authorities and industry join forces in regional working groups. Regional project teams developed packages of a large number of -small- measures to be implemented by these stakeholders.

The regional packages of measures will be funded by the regional authorities as well as by the national government. In judging these requests for funding, an important criterion in the assessment of the Dutch Ministry of Infrastructure is the cost-effectiveness of the measures. This is however no simple criterion to apply in practice, partly because there is no generally accepted definition based on which unambiguous quantification can take place, and because determining the effects of measures and associated costs is not easy. This is due to the rather general 
description available of the measures and the package as a whole. In addition, only a short time was available for the evaluation. To determine the cost-effectiveness of the regional packages of measures, a quick scan approach was developed (and applied) that is useful in judging the measures proposed. This approach will be applicable in firstround quick scan judgment of policy measures.

This paper presents and illustrates this quick-scan approach for assessing the cost-effectiveness of smaller and notwell demarcated transport measures that can be used as a first-scan while establishing packages to deal with certain transport problems. It adds to the available evaluation literature (see section 2 ) in relying on a combination of expert opinions as well as simple models rather than data intensive four-stage transport models. We aim to show that a quick-scan approach is available that gives plausible results and is useful for decision making in this area.

\section{APPROACHES FOR ESTABLISHING COST-EFFECTIVENESS}

Within the policy making process, there is a range of approaches which could be adopted to provide decision makers with an understanding of the implications of a policy/regulation (e.g. Annema et al., 2007; Bristow et al., 1997; Weisbrod et al., 1997). These range from qualitative approaches that rely on a description of the impacts to quantitative approaches which attempt to provide further detail on the nature, magnitude and significance of potential effects. And they range from reporting effects to integration of effects using frameworks like Cost-Benefit Analysis (CBA) and Multi-Criteria Analysis (MCA). Economics provides two approaches that fall into theformer category: $\mathrm{CBA}$ and cost effectiveness analysis.

Cost-effectiveness analysis (CEA) seeks to find the best alternative intervention that minimizes the costs of achieving the desired result. Analysts perform CEAs when the objectives of the public policy have been identified and expressed in only one indicator (e.g. reduction in the number of fatalities, $\mathrm{CO}_{2}$ emissions, or Vehicle Lost Hours due to congestion) and the only remaining question is to find the least cost-option of arriving at these objectives. CEA, therefore, does not ask, nor attempts to answer, the question whether the policy is justified, in the sense that its social benefits exceed its costs. One may use standards or rules of thumbs. For example, if it is known how much impact the desired policy realizes (e.g. reduction of Vehicle Lost Hours) one can estimate the cost per unit of the realized objective. If these costs are lower than the economic value of the effect, for example 15 Euros, the average VOT of each traveler, for each reduced vehicle lost hour, then one talks about a cost-effective measure. CEA has very often been applied in environmental areas, such as $\mathrm{CO}_{2}$ emissions reductions (e.g. Kok et al., 2012). It has also been applied to travel demand management (TDM). For example, Loukopoulos et al. 2004 discuss CEA for TDM, concluding that cost minimization approaches (how 'cheap' can one obtain results?) need not to be questioned, but the way they are applied is open for debate. This at least relates to selecting candidate policies and estimating their costs.

However, in some cases multiple effects and costs matter. For these situations, (Social) Cost-benefit analysis (CBA or SCBA) is an economic technique applied to public decision-making that attempts to quantify and compare the economic advantages (benefits) and disadvantages (costs) associated with a particular project or policy for society as a whole. It comprises not just the financial effects (investment costs, direct benefits like tax and fees, et cetera), but also non-financial economic effects (like the value of reductions in travel times and indirect (labor) market effects) as well as all the social and environmental effects, including emissions / pollution, safety, et cetera. The appeal of CBA is that by monetizing the benefits of the policy, it is possible to compare and/or aggregate many different categories of benefits with one another, and with the costs of the policy. CBA in The Netherlands can be based on the so-called OEI guideline (OEI represents Overview Effects Infrastructure) released in 2000 by the Dutch Ministry (Eijgenraam et al., 2000). This guideline indicates that for large national infrastructure projects an SCBA must be drawn, and how that should happen. For smaller projects an SCBA according to the OEI guideline may be implemented.

A major advantage of a social cost-benefit analysis is that it enables the decision makers to compare different project alternatives. Hence, these alternatives will not just be compared intrinsically, but will also be set against the "null alternative hypothesis". This hypothesis describes "the most likely" scenario development in case a project will not be executed. The social cost-benefit analysis calculates three types of effects: 
- Direct effects are the costs and benefits that can be directly linked to the owners/users of the project properties (e.g., the users and the owner of a building or freeway);

- Indirect effects are the costs and benefits that are passed on to the producers and consumers outside the market with which the project is involved (e.g., the owner of a bakery nearby the new building, or a business company located near the newly planned freeway).

- External effects are the costs and benefits that cannot be passed on to any existing markets because they relate to issues like the environment (noise, emission of $\mathrm{CO}_{2}$, etc.), safety (traffic, external security) and nature (biodiversity, dehydration, etc.).

SCBA is a much broader perspective than the so-called cost-effectiveness analyses (CEAs). However, whether there are large differences in the outcome will depend on the nature of the impacts. When there are a large number of different effects including indirect and external effects, to be taken into consideration, it seems more appropriate to use SCBA. However, in case relative simple objectives for policies are formulated a CEA seems more obvious to use.

In both the SCBA and the CEA, it is of great importance that the effects are assessed well and also that the costs are well defined. Measures aimed at improving the utilization of the network often involve reduction of travel times and increase of reliability and robustness of the system for road users. Safety and environmental issues are often not included in 'simple' evaluation of policy measures, because they are seen as conditions where the current situation should not get worse. In addition, other effects can be distinguished, such as effects on employment and exports, but these factors are not considered very important in such evaluations and excluded from the formal analysis. The methodology we describe is an example of a simple evaluation, and the evaluation only aimed to make a quick and rough shift in attractive versus not-attractive policy options. Hence, it was decided to carry out a CEA.

Regarding the cost of the measures it is important to take into account the so-called lifecycle costs, the costs over the total life of that object. It concerns both the construction costs as well as the costs for maintenance of the object. These costs must be made to the object to operate on a predetermined level of performance. The estimation of lifecycle costs yields a careful consideration of alternatives. When only the construction costs of a project looked at, the management and maintenance costs are ignored which are important in traffic and mobility management. In many cases there will be a tradeoff between spending on construction on one hand and spending on management and maintenance on the other hand. By taking the sum of the cost per project alternative or variant into account, the trade-off can be examined. This is important for efficient use of public funds. We used life cycle costs in the estimation of the cost-effectiveness - see step 5 of the approach, presented in the next section. We assume that the entire investment will be made in the base year, hence discounting is not necessary

\section{METHODOLOGY FOR QUICK-SCAN ANALYSES}

This section explains in detail how in practice the cost-effectiveness can be determined in a quick-scan manner. Note that the CEA is carried out in terms of cost per avoided lost vehicle delay hour. It does not reflect the welfare gain, as in a SCBA. There are indeed numerous social benefits are not included (reliability, safety, environment, robustness, additional travel benefits, etc). It is therefore a limited analysis.

\section{Step 1: Determination of the effects of demand measures}

This involves determining the effects of measures on the inflow in bottlenecks. These measures may reduce influx, which has a positive effect on the vehicle delay hours. Average effects can be derived in several ways. A relatively advanced way would be the use of meta-analyses of the effects of travel demand management measures. However, local municipalities do not always have access to studies, nor the capacity and knowledge for a met-analyses. Alternatives can be the use of model runs that ex ante evaluate candidate policy options, 'before-and-after' studies of already implemented policy measures, making use of practice oriented literature, and estimations of experts. To this end, the following steps may be taken, in which the sequence is not fixed:

\section{A. Estimate reduction of total peak demand with travel demand management measures (TDM)}

1. Determine the total "direct" effect of TDM in terms of the number or proportion of vehicles that will leave the peak (but fail to switch to public transport or bicycle). This reflects the effects of measures that help to 
reduce the number of trips (for example, telecommuting), number of kilometers (to live closer to work) or promote off-peak travel (flex-time). These measures ensure fewer trips / kilometers with the car in peak hours;

2. Determine by a pragmatic quick scan traffic assignment procedure (e.g. using expert assessments, team analysis) the reduction in the number of vehicles that will use certain corridors or road segments.

B. Estimate effects of measures that promote alternative modes of transport in peak hours (bike, public transport)

1. Determine the increase in the use of alternative modes of transport during peak hours, given the fact that some people did already stop making trips in the peak (see A) by complementary measures that promote the use of bicycle and / or stimulate transit;

2. Determine the travel mode choice that would have been made without the measures, or at least, the share that otherwise would have used the car. In this study it is assumed that approximately $1 / 3$ of the total (new) use is substitution from car to another mode. The other $2 / 3$ of the growth is induced demand (additional travel by bicycle or public transport). These shares are based on many empirical and modeling studies. ;

3. Determine, using a pragmatic assignment procedure (e.g., expert assessments, team analysis), the decrease in the number of vehicles entering a bottleneck.

\section{Estimate effects of measures that promote use of alternative routes}

Finally, the influx of traffic to be reduced with specific traffic management measures, such as stimulating use of alternative routes, is estimated. Measures might include route information (in-car or roadside). The change in demand can be determined as follows:

1. Determine the expected percentage change in car users changing route at a decision point in the network, based on expert knowledge. This requires, amongst others, an estimate of the number of car drivers with an alternative, comparable alternatives, etc. or rules of thumb (4\% to $12 \%$ may change routes);

2. Determine the changes in traffic demand that result, for both the main route as well as the alternative.

Additional issues. If there are packages in which related measures are combined, an estimate should be made of the combined effect of the measures, if this combined effect differs from the sum of both measures. This interaction effect can be positive or negative depending on the question whether the measures are mutually reinforcing or weakening. Suppose measure 1 (M1) leads to a 1\% decrease of the traffic intensities and measure M2 to a decrease of $2 \%$. The combined effect (without interaction effects) is then a decrease of $3 \%$ (calculated on the basis of the 'remaining fractions': $0.99 * 0.98 \approx 0.97)$. The minimum effect, which acts as the measures fully overlap is max (M1 and M2) $=0.98$. The actual effects will often lie in between them. In some cases, measures reinforce each other. For example, building a railway station $2 \mathrm{~km}$ from a business area has little impact on transport mode choice of commuters if it is not connected with the individual plants in the area, while construction of a bicycle path connecting the station area and the business area will have little effect on mode choice if there is no railway station. The combination of both measures has much more effect than the sum effect of both measures separately.

From demand influencing measures so-called rebound effects might be expected: the measures will create "free space". E.g. a reduction in car use during the peak hours will be (at least partially) lead to a 'back to the peak hour' effect of car users that now avoid the peak hours. The "net" effect of the measures will therefore be lower than the initial effect. Although the proposed quick scan method does not explicitly account for this effect, the impact could be included by means of expert judgment if deemed relevant and considerable.

\section{Step 2: determining effects of dynamic traffic management and infrastructure enhancements}

In this step, measures are assessed which have an impact on the capacity of the road. The packages usually can change capacity with a few percent. Included are measures that change the probability of an incident. For other measures, capacity reduction due to incidents has to be estimated. For these estimates rules-of-thumbs have been used. These are derived from a meta-analysis of evaluation studies of traffic and demand management studies carried out by MuConsult (2010). A brief overview of the results is presented in table 1. 
Tab 1: Some results of the meta-analysis on effects of traffic management measures

\begin{tabular}{|l|l|l|}
\hline Instrument & Impact factor & Effect \\
\hline Tidal flow & capacity & $5-25 \%$ \\
\hline Ramp Metering & capacity (effective) & $0-5 \%$ \\
\hline VMS & Route choice & $4-12 \%$ \\
\hline Automatic incident detection & Traffic jam warnings & $\begin{array}{l}15-40 \% \text { less accidents, } 0-1 \% \\
\text { increase capacity }\end{array}$ \\
\hline $\begin{array}{l}\text { Take-over prohibition for } \\
\text { trucks }\end{array}$ & capacity & $-4-+4 \%$ \\
\hline Network management & $\begin{array}{l}\text { capacity (effective), route } \\
\text { choice }\end{array}$ & $20-30 \%$ \\
\hline
\end{tabular}

Source: MuConsult, 2010

\section{Step 3: determine effects using surplus of vehicles per bottleneck}

An important element in determining the effect is that one determines the effects on the vehicle delay hours in relation to the amount of 'excess traffic' (the extent to which demand exceeds capacity) at a bottleneck. Sometimes, it is assumed as a rule of thumb that a change of $1 \%$ in the capacity and/or intensity will lead to a change in the VLH (vehicle loss hours) with $2-4 \%$. This is not necessarily an adequate assumption. For example, in specific situations, a single vehicle can cause a bottleneck, so that the percentage effect of reducing the car with a far greater impact.

Therefore, better approaches are used in our quick-scan. For the freeways in The Netherlands, Transpute (2011) estimated for each bottleneck the number of excess vehicles, the removal of which either reduces the maximum delay at a bottleneck to 10 minutes (the so-called $\mathrm{x}$-factor), or completely removes all delays.

Step three consists of three key sub steps. First, for all considered bottleneck locations, the demand patterns are reconstructed (step 3.1). Rather than using complex OD estimation approaches, the demand pattern reconstruction method is based on a technique similar to a Fourier series analysis in which the contribution of specific signals (called tones) $f_{i}(t)$ to the total demand $f(t)$ is reconstructed from the measured flows at the bottleneck location:

$$
f(t)=\sum_{i} \beta_{i} \cdot f_{i}(t)
$$

The tones have been determined for situations where congestion did not occur, and describe typical patterns (e.g. morning or evening commute, off-peak demand pattern). Based on estimates of the capacity $C$ at the considered bottleneck, a standard queuing model (Hoogendoorn and Bovy, 2001) is used to determine the vehicle loss hours $(V L H)$ at this bottleneck location (step 3.2). Since the capacity is the only unknown parameter is a queuing model, the capacity can be set such that the predicted vehicle loss hours match the measured vehicle loss hours sufficiently. In step (3.3), the traffic surplus is determined by lowering the demand such that no congestion occurs. Also, the traffic demand reduction leading to a maximum vehicle delay of 10 minutes is determined. The latter demand is referred to as the $x$-factor. The table below provides an overview of the top-10 bottlenecks, the annual vehicle loss hours, the traffic surplus and the $\mathrm{x}$-factor for both the morning and the evening peak.

Tab. 1 Overview of bottleneck characteristics (selection) stemming from Transpute (2011) study.

\begin{tabular}{|l|l|r|r|r|r|r|r|}
\hline Freeway & Bottleneck site & \multicolumn{3}{|c|}{ Morning peak } & \multicolumn{3}{|l|}{ Evening peak } \\
\cline { 3 - 9 } & & VLH & Surplus & $\begin{array}{l}\text { x- } \\
\text { factor }\end{array}$ & VLH & Surplus & $\begin{array}{l}\text { x- } \\
\text { factor }\end{array}$ \\
\hline A20 & Hoek van Holland - Gouda (Rotterdam & 1450 & 950 & $0 \%$ & 4680 & 2150 & $4.6 \%$ \\
& Crooswijk) & & & & & & \\
\hline A2 & Amsterdam - Den Bosch (Oudenrijn) & 1210 & 800 & $0 \%$ & 4020 & 1850 & $3.8 \%$ \\
\hline A1 & Amsterdam Apeldoorn (Diemen) & 0 & 0 & $0 \%$ & 4500 & 2050 & $4.3 \%$ \\
\hline A28 & Utrecht - Zwolle (De Uithof) & 40 & 50 & $0 \%$ & 3150 & 1400 & $4.5 \%$ \\
\hline A4 & Amsterdam - Delft (Hoogmade) & 2570 & 1100 & $4.0 \%$ & 2250 & 1050 & $3.0 \%$ \\
\hline
\end{tabular}

In illustration, the table shows that on the A2 motorway near Oudenrijn, the total delay for each evening peak is on average 4020 vehicle-hours. To get rid of all delays during the evening peak, a total of 1850 vehicles are to be 
'removed'. Removing the total demand in the evening peak with 3.8\% (x-factor) ensures that the maximum delay encountered by any vehicle is 10 minutes.

\section{Step 4: determining effects on change vehicle hours}

The results of previous steps are input for calculating the effects on vehicle loss hours. By implementing certain traffic management measures we can increase the capacity of the bottleneck. This decreases the loss hours. The extent to which depends on the degree of surplus and thus differs from day to day. In the calculations we use an average (annualized) value, in most cases for all working days. By using TDM measures we can achieve some reduction in demand. This reduces the loss hours even more. The extent to which again depends on the extent of the surplus.

Let us briefly explain how this has been achieved. The bottleneck analysis presented in step 3 forms the basis for the approach. Using the data for all considered bottlenecks allows us to determine a relation between the vehicle loss hours and the demand surplus that shows a remarkable crisp relation (given that these data are determined for different locations, for morning or evening peaks, etc.). Fig. 1 shows this relation, including a polynomial fit stemming from the data. We find the following relation between the vehicle loss hours $(V L H)$ and the surplus $s$ :

$$
V L H(s)=0.0005 \cdot s^{2}+1.2389 \cdot s
$$

The $R^{2}$ equals 0.95 , showing that this is indeed a very good fit. Using this relation, it is easy to find estimates for the impact of demand reducing measures (e.g. mobility management).

However, with a bit more effort, it is also possible to determine the impact of traffic management measures. Let us briefly describe the approach. For each of the bottleneck locations, we determine the period $T_{\text {peak }}$ how long demand is larger than capacity. Since we know the demand surplus $s$, we can equivalently determine the capacity shortage $\Delta C$ by:

$$
\Delta C=s / T_{\text {peak }}
$$

Let $z$ denote the relative capacity increase (e.g. due to a traffic management measure). We can now determine a new relation between the surplus $s$ and the vehicle loss hours $V L H^{\prime}(s)$ by using the following formula:

$$
V L H^{\prime}(s)=V L H(s) \cdot \max \left\{1-\frac{z \cdot C}{\Delta C}, 0\right\}
$$

In this equation, the factor $1-z \cdot C / \Delta C$ denotes the reduction in the vehicle loss hours due to the relative capacity increase $z \cdot C$. Note that when this increase is equal to the capacity shortage $\mathrm{D} C$, then the factor is equal to zero and the resulting vehicle loss hours are (logically) also equal to zero. The red line in Fig. 1 shows the resulting relation between the vehicle loss hours and the surplus, assuming a 5\% capacity increase. 


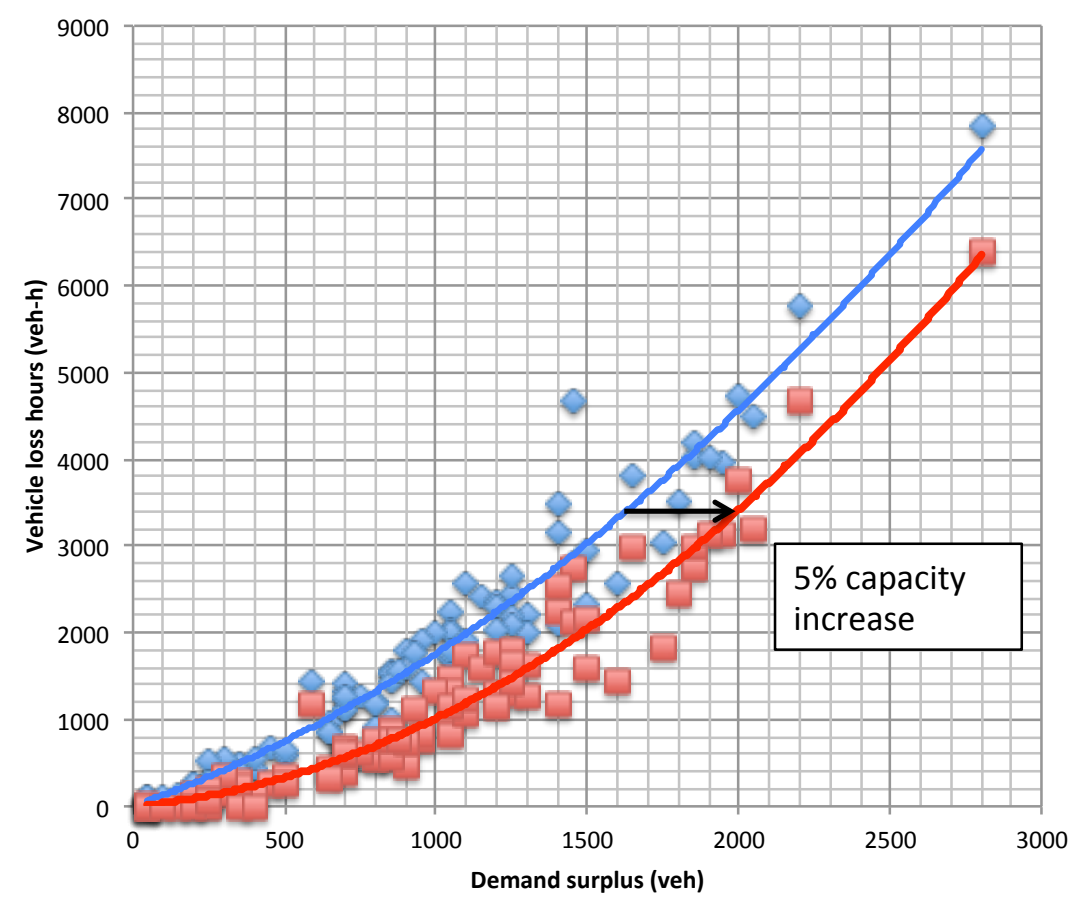

Fig. 1 Average relation between demand surplus and the vehicle loss hours. The blue dots and curve show the relation based on the bottleneck data described in step 4 . The red dots and curve show the translated relation assuming a $5 \%$ capacity increase.

\section{Step 5: Determining Cost-effectiveness.}

Based on the previous steps we obtained a quantitative estimate of the change in Vehicle Lost Hours of (combinations of) measures. If insights are also obtained in the cost of the measures, then the cost-effectiveness can be established. We can define a threshold value for the savings of vehicle loss hours per unit of currency (euro) to label a (combination of) measures as cost-effective. In establishing the cost-effectiveness ratios, we assume:

- Investments are amortized over 6 years;

- We consider lifecycle costs, including management and maintenance $(10 \%$ per year of the initial investment);

- We used generally accepted values of time (VOTs), and assumed an increase in VOT over time reflecting income increase, in line with the CBA practices in the Netherlands. On the basis of these assumptions, it appears that:

○ 1 million investment for 6 years requires a minimum annual savings of 20-25,000 vehicle hours per year or 130-160 per day;

- For 1 million operating subsidies, a reduction of vehicle loss hours of 75-80,000 hours per year is needed or around 500 per day, to achieve cost effectiveness.

This completes the five-step quick scan assessment approach. To gain insight into the workings of the approach and the plausibility of the resulting outcomes, let us now apply the method to a test case example.

\section{EXAMPLE: SMART PEAK PRICING IN ARNHEM-NIJMEGEN}

The measure considered

The idea of road pricing has been around for a long time, but there exists significant resistance against introducing a price for a commodity - access to public roads - that has been freely available for such a long time. Despite the clear economic case for marginal cost pricing, it may therefore be helpful to explore alternative possibilities to alleviate congestion, that are hopefully more appreciated by the public. In addition, advanced road pricing systems are not easy to implement within a few years, making them not pass the ' 2014 criterion' as applied in this project. An obvious possibility would be to think about the use of 'rewards' instead of tolls or 'penalties'. Even though economists point out all sorts of negative aspects of such a measure (e.g. Rouwendal et al., 2012), there may be 
reasons to consider rewards anyway. A reward system may be less effective and efficient in combating congestion than a tolling system. But if the latter is infeasible for political reasons, a more relevant comparison is between a reward system and the absence of any control through financial incentives. Rouwendal, et al (2010) show that with inelastic demand a (time varying) reward is equivalent to a toll, and to a continuum of combinations of time varying tolls and rewards (including fine fees). When demand is price sensitive, a reward becomes less attractive from the efficiency viewpoint, because it attracts additional users to the congested bottleneck. As a result, both the secondbest optimal rate of participation in the scheme, and the relative efficiency that can be achieved with it, was found to decrease when demand becomes more elastic. The idea was tested on a small scale in an experiment called 'Spitsmijden' (Avoiding the Peak) documented in Knockaert, Verhoef and Rouwendal (2009). They describe the first outcomes of an experiment in which regular car travelers were stimulated to change their behavior by offering them positive monetary incentives or credits to obtain a smartphone. During a ten-week test period, participants in the experiments were confronted with different variants of monetary incentives and credit to earn a smartphone. The results suggest that all types of incentives resulted in a considerable reduction of the percentage of peak car trips of participants. The initial percentage of about $45-50 \%$ peak car trips could be reduced to about $20 \%$. The primary response to incentives is to retime the car commute to the periods before and after the morning peak. Mode switches only accounted for a relatively small share of the reduction in peak car traffic.

\section{Implementation in a new region}

Based on this and other experiments in The Netherlands a larger scale application of the measure was implemented in the region Arnhem-Nijmegen. The project is called 'Smart Pricing'. In this example it is shown how the surplus is calculated and how the effects on VLH's and financial benefits are calculated (step 3 to 5 of the methodology).

\section{Smart Pricing project}

The primary goal of the project is to keep traffic circulating on the regional ring road network surrounding the medium sized Dutch cities Arnhem and Nijmegen, despite large-scale road works are to be carried out. This goal has to be achieved by an efficient planning of road works and by reducing the number of vehicle kilometers during peak hours ( 7 am -9 am, $3.30 \mathrm{pm}-6.30 \mathrm{pm}$ ) by 3\%. Fig. 2 shows this circular network called RegioRing consisting of various roads in green.

Smart Pricing started in September 2010 and lasted until the end of June 2012. In March 2012 there were 14,870 active participants. Each of these participants received a budget which can be as high as $€ 1,500$,- per year. For every trip that is made on the RegioRing during peak hours $€ 4$,- is subtracted from the budget. These participants are detected by a camera system. In March 2012, 35\% trips were reduced during peak hours by the participants. This resulted in 5,310 'peak avoidances' per day with an estimated reduction of vehicle kilometers of 95,580 kilometers per day (average trip length is 18 kilometers). It is estimated that on average $4.5 \%$ reduction in the amount of traffic was achieved. 


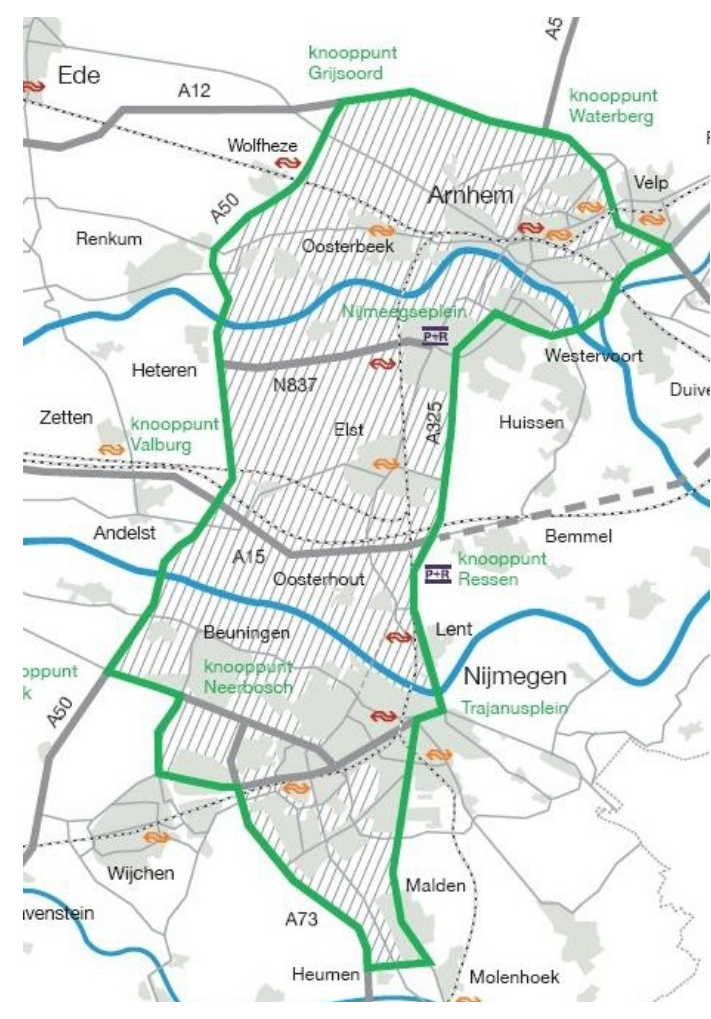

Fig. 2: The Arnhem-Nijmegen region

\section{Cost effectiveness of the program}

It is the intention of the regional government to continue the program in a modified form (e.g. an alternative reward system with non-financial incentives). In the decision process on the continuation of the program, the costeffectiveness is an important aspect. Therefore the question was raised what the effects of Smart Pricing in 2011 were and how these related to the total yearly costs of the program.

To answer this question the effects on the VLHs had to be estimated. Together with the value of time (VOT) the financial benefit of the program can be calculated. A so called 'what if' approach was used: how many more vehicles would have been observed without the Smart Pricing project compared to the (existing) situation with this project and what would have been the effects of the larger number of vehicles on the VLHs on the RegioRing. In this approach the existing traffic situation including the effects of Smart Pricing (in 2011) is the reference situation.

The estimation procedure, using the quick scan appraisal method consisted of the next steps:

1. Collecting data on VLHs in 2011. Data for VLHs during morning peak and evening peak for a regular working day were based on data from the roadside measuring system on the various trajectories (road sections from intersection to intersection) of the RegioRing (see first two columns in table 2). These data were provided by the NDW (National Database for Road-traffic data). It has to be noted that in the year 2011 the Smart Pricing project was already running. So the data already contained the effects of fewer vehicles through the Smart Pricing project.

2. From these data the surplus of vehicles $(s)$ was estimated from the observed VLHs using the following formula which was derived from (2):

$$
s(V L H)=\sqrt{1534873+2000 \cdot V L H}-1239
$$

See the third and fourth column in Tab. 2 for the estimated surplus.

3. In the previous step the surplus $(s(V L H))$ that belongs to the observed VLHs is calculated. These include the 
effects of Smart Pricing. In order to estimate the effects of avoiding the RegioRing during the peak we carry out the 'what if' analysis: how many VLHs would have been observed without Smart Pricing? To answer this question we have to know how many vehicles avoided the morning and evening peaks in the year 2011. From the available data this was estimated to be on average per trajectory around 400 vehicles during the morning peak and 600 vehicles during the evening peak. These numbers were added to the surplus, calculated in step 2 . In the fifth and sixth column of Tab. 2 the surplus including the 'avoiders' is shown. So, this is the expected (larger) surplus of vehicles without the Smart Pricing program.

4. Based on the surplus, including the vehicles avoiding the peaks, VLHs were calculated representing the situation without the Smart Pricing program by applying formula 1.2. See the last two columns of Tab 2.

10

\begin{tabular}{|c|c|c|c|c|c|c|c|c|}
\hline & \multicolumn{2}{|c|}{ VLH Observerd } & \multicolumn{2}{|c|}{ Surplus (estimated) } & \multicolumn{2}{|c|}{ Surplus incl. avoiders } & \multicolumn{2}{|c|}{ VLH's incl. avoiders } \\
\hline Peak & Morning & Evening & Morning & Evening & Morning & Evening & Morning & Evening \\
\hline Trajectory 1 & 2,756 & 184 & 1,416 & 140 & 1,816 & 740 & 3,898 & 1,191 \\
\hline Trajectory 2 & 1,480 & 1,322 & 881 & 805 & 1,281 & 1,405 & 2,408 & 2,728 \\
\hline$\ldots$ & $\ldots$ & $\ldots$ & $\ldots$ & $\ldots$ & $\ldots$ & $\ldots$ & $\ldots$ & $\ldots$ \\
\hline
\end{tabular}

\section{Tab. 2: VLHs and surplus of vehicles in the morning and evening peak}

Now the difference in VLHs can be calculated in the situation with and without smart pricing. The VLHs including avoiders (situation without Smart Pricing, last two columns) are compared to the observed VLHs (situation with Smart Pricing). It can be seen that the reduction in VLHs for trajectory 1 equals $-29 \%((2.756-3.898) / 3.898 * 100)$ in the morning and $-85 \%$ in the evening. For trajectory 2 these figures are $-39 \%$ and $-52 \%$ respectively.

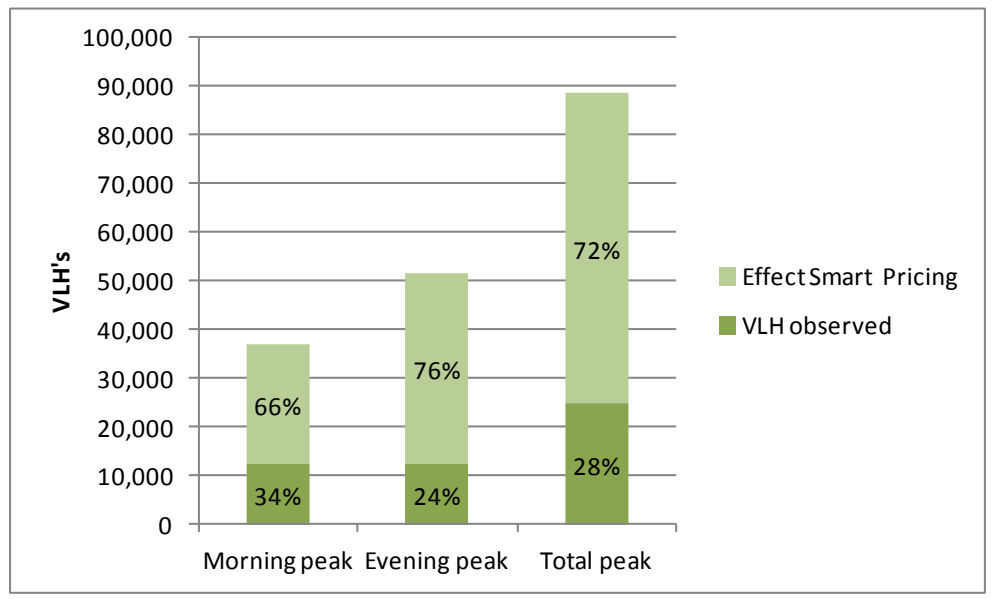

Fig. 3: Results of the quick scan appraisal

Fig. 3 shows the final results of the quick scan appraisal. The effect of Smart Pricing in the morning peak was a $66 \%$ VLH-reduction. In the evening peak this reduction was $76 \%$ and the total reduction was $72 \%$.

To calculate the financial benefits per year the VLHs per working day (64.000 VLHs per day) have to be multiplied by the number of working days ( 225 per year) and the VOT ( $€ 15$,- taking into account car occupancy and share of freight). This results in a total benefit of $€ 214$ million. This is far more than the total costs per year: $€ 4.5$ million.

It is important to realize that, as explained above, we only focus on cost-effectiveness of the measure. Additional effects, such as lower emissions and concentrations of pollutants, less noise nuisance and maybe improved safety (all positive) are ignored, as well as welfare changes due to behavior changes of travelers. In case of introducing road pricing these behavioral changes are negative: people 'lose' welfare if they travel less, switch mode or time-ofday. However, in our case they are positive because they result from a positive financial incentive (reward). Following the generally applied 'rule of half' in economic analyses of transport policies the positive value for those travelers who change behavior on average is half of the financial incentive. All in all we conclude that if other 
effects would be included, the benefit-to-cost ratio would be even higher than in our cost-effectiveness analyses. Therefore we think that the limited scope of our analysis in this example is not a problem for decision making.

It has to be noted that a so called 'back to the peak' reaction could occur: travelers who do not participate in the project take advantage of reduced congestion and shorter travel times and consequently increase their use of the RegioRing. Although this reaction can lead to a substantial reduction of the total effect it is not known so far from the available monitoring data to what extent such a reaction occurred. This effect probably reduces the costeffectiveness of the policy because the reduction in congestion is lower than we assumed. On the other hand, those who change behavior ('back to the peak') face welfare gains: they benefit because of the change in time-of-day. Based on many studies in the area or road pricing we expect these benefits to be lower than the disadvantages of a lower reduction in congestion. Therefore we conclude that ignoring the 'back to the peak' effect results in an overestimation of the cost-effectiveness of the policy. But because benefits are so much higher than the costs the policy very likely will be very cost-effective.

\section{CONCLUSIONS}

When deciding on investments in traffic management and travel demand management, decision makers wish an overview of expected impacts of project alternatives and associated costs. In the case of smaller projects aimed at specific targets without major side effects it is sufficient to obtain a simple overview of the social effects and the associated investment. This is a form of Cost Effectiveness Analysis. In the case of Transport System Utilization Programs considered this seems to give appropriate detail for a first scan of relevant measures. This paper demonstrates a simple approach to look at the cost effectiveness of these measures. We have illustrated the approach by looking at a project aimed at avoiding peak travel in The Netherlands, showing the applicability or our method and the plausibility of the outcomes.

We conclude that the proposed method is applicable for providing a first, quick scan assessment. This assessment turns out to be useful in the first selection of packages of measures, to support policy makers that need to choose in which (selection of) measures they need to invest, even if these measures have not yet been described or designed at a very detailed level.

\section{REFERENCES}

Annema, J.A., C. Koopmans, B. van Wee (2007), Evaluating transport infrastructure investments: the Dutch experience with a standardized approach. Transport Reviews Vol. 27 (2) 125-150

Bristow, AL, A. D. Pearman \& J. D. Shires (1997) An assessment of advanced transport telematics evaluation procedures, Transport Reviews: A Transnational Transdisciplinary Journal Volume 17, Issue 3 p 177-205

Eijgenraam, C.C.J., C.C. Koopmans, P.J.G. Tang, A.C.P. Verster (1999), Evaluatie van infrastructuurprojecten. Leidraad voor kosten-batenanalyse. Deel I: Hoofdrapport. Onderzoeksprogramma Economische Effecten Infrastructuur. Den Haag, Ministerie van V\&W en EZ

Ettema, D; J. Knockaert and E. Verhoef (2010). Using incentives as traffic management tool: empirical results of the "peak avoidance" experiment. Transportation Letters: The International Journal of Transportation Research (2010) 2: (39-51)

Hoogendoorn, S.P., Bovy, P.H.L. (2001). Proceedings of the Institution of Mechanical Engineers. Part I: Journal of Systems and Control Engineering 215 (4), pp. 283-303

Rouwendal, J, E.T. Verhoef, J. Knockaert (2012), Give or take? Rewards versus charges for a congested bottleneck. Regional Science and Urban Economics 42 (1-2), pp. 166-176

Kim (2010, 2011) Mobiliteitsbalans. Technical report. Kennisinstutuut Mobilitieit (in Dutch). Ministry of Infrastructure and the Environment

Knockaert, J., E.T. Verhoef and J. Rouwendal (2009) “The Spitsmijden experiment: reward to battle congestion" TRB 88th Annual Meeting

Kok, R., J.A. Annema, G.P. van Wee (2011), Cost-effectiveness of greenhouse gas mitigation in transport: A review of methodological approaches and their impact. Energy Policy, 39 (12), pp. 7776-7793. 
Loukopoulos, P. C. Jakobsson, T. Gärling, C.M.. Schneider, S. Fujiic (2004), Car-user responses to travel demand management measures: goal setting and choice of adaptation alternatives. Transportation Research Part D 9 (4) pp. $263-280$

Ministry of Infrastructure and Environment (2010) Beter Benutten Brief. Ministry of Infrastructure and the Environment.

MuConsult (2010). A qualitative meta-analysis of the effects of utilization measures. Report for the Dutch Ministery of Infrastructure and the Environment.

Weisbrod, G. and B. Weisbrod (1997), Assessing the Economic Impacts of Transportation Projects: How to Choose the Appropriate Technique for Your Project, Transportation Research Board, National Research Council, Washington. 